\title{
The humanistic side of medical education
}

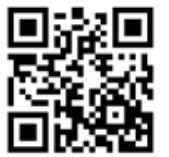

The influential Flexner report of 1910 was the precursor of innovation in modern medical curricula, and by correctly placing knowledge of the human body and of biological science at the centre of medicine, great strides were made in medical education and practice.

William Osler in his 1919 presidential address to the British Classical Society entitled 'The old humanities and the new medicine' described how 'Scientific education and the humanities should inform each other ... The humanities are the hormones ... which do for society at large what the thyroid gland does for the individual.: ${ }^{[1]}$ Less attention was paid to this recommendation for medical education, despite Osler's status as a revered clinician and teacher

One hundred years after the Flexner Report recommended major changes to medical education, an international panel has released a vision of medical education for the 21st century. ${ }^{[2]}$ The report calls for doctors to be transformative leaders and team workers for change in a very different and globalised world. The judicious application of modern medical knowledge and technological skills in the practice of medicine unquestionably requires the ability to work effectively in multidisciplinary teams and to have appropriate attitudes to patients and colleagues. The same applies to undertaking medical research for the advancement of knowledge.

This new international report briefly notes the importance of ethics, and values are mentioned several times. However, no account is offered of either the values that should be exemplified in health professional education, or the content and method of ethics education relevant to 21 st-century healthcare.

Humanistic attributes relevant to healthcare include the ability to listen to and observe sensitively all aspects of our shared human vulnerability and frailties, with appreciation of the diversity of social, cultural and environmental differences that shape people's lives and health in myriad ways. Moral imagination helps us to see ourselves in the 'other' (especially in multicultural and class-differentiated societies), and to have compassion and empathy for suffering and the stresses of lives that may be very different from our own. Never to be forgotten is the imperative to respect the uniqueness and individuality of every person and to have an existential appreciation of life's value and its finitude. Sensitivity to ethical dilemmas is also crucial.

While these attributes have long been valued as an essential aspect of medical practice, they have received much less formal attention in medical education. However, in recent decades there has been a re-emphasis on teaching the humanities in medicine. ${ }^{[3-5]}$ Methods used to instil or promote such qualities in aspirant practitioners range from theoretical courses in the humanities, including ethics, through practical uses of art, music and narratives in literature and theatre to illustrate human life in all its agonising varieties. ${ }^{[5,6]}$ More recently, the role of 'virtue as excellence' in the practice of medicine has been promoted. ${ }^{[7]}$ Virtuous traits encompass rigour and objectivity as intellectual abilities, and such ethical attributes as honesty, compassion and temperance. These virtues derive from commitment to excellence as the internal purpose of the professional role and from the habits of working practically and self-reflectively within one's professional field.

The hope of teaching the humanities in medicine is that improvement in attitude and practice may result from sensitising students to the many complex social and ethical issues faced in healthcare, and through providing them with insight into the role of moral reasoning in ranking potential solutions with justifying reasons and transparency. ${ }^{[8]}$ Clearly, good examples shown by established clinicians and teachers at the bedside and by leaders who set institutional and national policies could inspire emulation by new generations of health professionals.

Excellence in all these aspects of practice provides the grounds for inspiring confidence, trust and hope without deceit, and trust remains an important ingredient in the medical context. Those who have experienced the internal satisfaction of caring well for fellow humans and who have benefited from such care themselves, become more aware of this critically important role of healthcare professionals.

The humanities sensitise us to comprehend that the achievement of good health is dependent on more than the provision of healthcare. The foundations of good health lie in better living conditions and other social and societal determinants of health that optimise maternal and child health and provide a good start to life. These are the precursors for improving lives that can then benefit further from modern medicine. ${ }^{[9]}$ Healthcare cannot be seen in isolation, and changes in medical education and healthcare services are more likely to be implemented successfully if associated with improvements in these other spheres of our lives. ${ }^{[10]}$ Healthcare professionals can contribute on all these fronts through their clinical skills and humanistic practices, and by being agents for constructive progress in their communities and globally at a very challenging time in history.

\section{Solomon Benatar}

Bioethics Centre, University of Cape Town, South Africa, and Joint Centre for Bioethics, University of Toronto, Canada solomon.benatar@uct.ac.za

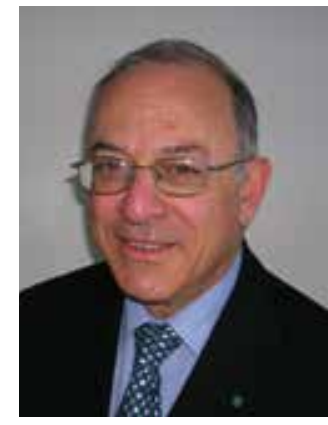

1. Osler W. The Old Humanities and the New Science. Boston: Houghton Miflin, 1920:26-28.

2. Frenk J, Chen L, Bhutta ZA, et al. Health professionals for a new century: Transforming education to strengthen health systems in an interdependent world. Lancet 2010;376(9756):1923-1958. [http:// dx.doi.org/10.1016/S0140-6736(10)61854-5]

3. Benatar SR. The humanities in medicine at UCT. S Afr Med J 1997;87(12):1662-1664.

4. Seggie J. Medicine and the humanities: Doctors as artists. S Afr Med J 2014;104(2):92. [http://dx.doi org/10.7196/SAMJ.7936]

Reid S. The 'medical humanities' in health sciences education in South Africa. S Afr Med 2014;104(2):109-110. [http://dx.doi.org/10.7196/SAMJ.7928]

Kumagai AK. A conceptual framework for the use of illness narratives in medical education. Acad Med 2008;83(7):653-658. [http://dx.doi.org/10.1097/ACM.0b013e3181782e17]

Benatar SR, Upshur R. Virtue in medicine reconsidered: Individual health and global health. Perspect Biol Med 2013:56(1):126-147. [http//dx doi.org/10.1353/pbmidal healt

Benatar SR, Benatar D. From medical manners to moral reasoning: An historical overview of Bioethics Benatar SR, Benatar D. From medical manners to moral reasoning: An his 2;102(6):406-408.

Birn A-E. Addressing the societal determinants of health: The key global health ethics imperative. In: Benatar S, Brock G, eds. Global Health and Global Health Ethics. Cambridge: Cambridge University Press, 2011:37-52. 10. Mayosi BM, Benatar SR. Health and health care in South Africa: 20 years after Mandela. N Engl J Med 2014;371:1344-1353. [http://dx.doi.org/10.1056/NEJMsr1405012

S Afr Med J 2015;105(1):3. DOI:10.7196/SAMJ.9043 